\title{
Activity and Residual Effect of Two Formulations of Lambdacyhalothrin Sprayed on Palm Leaves to Rhodnius prolixus
}

\author{
Miguel Angel Mazariego-Arana ${ }^{+}$, Eduardo Ramírez-San Juan*/++, \\ Ricardo Alejandre-Aguilar*/, Benjamín Nogueda-Torres*/++
}

\begin{abstract}
Facultad de Ciencias Químicas, Campus IV, Universidad Autónoma de Chiapas, km 1.5 Carretera Puerto Madero, 30700
Tapachula, Chiapas, México *Escuela Nacional de Ciencias Biológicas, Instituto Politécnico Nacional, Colonia Santo Tomás, México, D.F.

The insecticidal activity and residual effect of two formulations of lambdacyhalothrin were evaluated with Rhodnius prolixus; laboratory and field tests were conducted in the State of Chiapas, Mexico.

The results indicate that the lethal concentrations of the active ingredient of $S C\left(L C_{50}=2.37\right.$ and $L C_{90}=8.5$ $m g$, a.i. $/ \mathrm{m}^{2}$ ) were 4-8 times than those with the insecticide WP applied on R. prolixus bugs in palm leaves, a common building material for thatched roofs. Other investigators in South America recommended applying $30 \mathrm{mg}$ a.i./. $\mathrm{m}^{2}$ in porous materials; we obtained that the products WP and SC were 3.5 and 16 times more effective on palm leaves. Regarding the evaluation of the residual effects in field spraying, there was up to 15 months persistence after the application of WP in two doses $\left(8.6 \mathrm{mg}\right.$ a.i. $/ \mathrm{m}^{2}$ and $3.752 \mathrm{mg}$ a.i. $\left./ \mathrm{m}^{2}\right)$ with SC. We consider R. prolixus highly susceptible to the employed pyrethroids; they could be used to control this vector in the state of Chiapas, Mexico.
\end{abstract}

Key words: Rhodnius prolixus - Chagas disease - pyrethroids - vector control - Chiapas - Mexico

American trypanosomiasis is a zoonosis of great importance in Latin American countries and is produced by the hemoflagellate parasite Trypanosoma cruzi. This protozoan lives and proliferates in the gut of blood-sucking Reduviidae insects and can be transmitted to humans, producing heart and intestinal lesions described as Chagas disease (Ferro et al. 1995). Transmission by insect vectors represents $80 \%$ of all the cases of this illness (Dias \& Schofield 1999).

The "domestic" species of triatomines, the most important vectors of Chagas disease, are very sensitive to control sprayings with modern insecticides and changes to hygienic house conditions. In this case the determination of the basic susceptibility of the target vector, as well as the residual effect of the product (OPS 1984) is of major importance.

Considering the success of the Southern Cone initiative, and the Andean initiative in 1997 as a reference, the success of the Central American initiative for the control of Chagas disease vectors (Moncayo 1999, Ponce 1999) was promising.

Our results from previous studies conducted during 1997-2000 in the state of Chiapas, Mexico, indicate that Rhodnius prolixus is the main vector in houses in the rural areas in the Guatemala border. Several authors consider $R$. prolixus as good candidate for eradication in

Work supported by CONACYT, PROMEP and SIINVUNACH.

${ }^{+}$Corresponding autor. Fax: +52-962-51555. E-mail: mmazariego@hotmail.com

${ }^{++}$Fellowship of COFAA-IPN

Received 7 March 2001

Accepted 8 January 2002
Central America (Schofield \& Dujardin 1997, Dujardin et al. 1998, Ponce 1999). On the other hand Triatoma dimidiata, distributed in the wild in the coastal areas of Chiapas could not be considered as a candidate for eradication (Dias \& Schofield 1999, Acevedo et al. 2000).

The purpose of this paper, was to carry out a biossay to determine mortality of laboratory grown $R$. prolixus fifth-instar nymphs when exposed to contact with three doses of two formulations (WP and SC) of lambdacyhalothrin under laboratory conditions and to determine the residual effect on $R$. prolixus applying the insecticide on palm leaves roofs in field conditions. $R$. prolixus is considered the most important triatomine species in the state of Chiapas, Mexico.

\section{MATERIALS AND METHODS}

Triatomines - The tests were performed on fifth-instar nymphs of $R$. prolixus bugs obtained from a colony maintained in our laboratory at $29 \pm 1^{\circ} \mathrm{C}, 87 \pm 3 \% \mathrm{RH}$, and fed on rabbits once per week (Ryckman 1951). These bugs come from insects captured inside houses in Palenque, northern Chiapas.

Susceptibility to insecticide - Ten fifth-instar nymphs were placed on palm leaves previously sprayed with lambdacyhalothrin (Commodore ${ }^{\circ}$ WP 10 and Demand $\AA$ SC 2.5) by $60 \mathrm{~min}$ and observing the percent of mortality after 24 h (Mazariego-Arana 1997). Palm leaves were treated with two surfaces each time for different dose and each of these tests were repeated at least three times. In the control group were used palm leaves not treated previously. The percentage of mortality obtained with each dose were plotted in a log-probit scale with the help of a computer program (Raymond 1996). The $\mathrm{LC}_{50}$ and $\mathrm{LC}_{90}$ were then obtained, together with the $95 \%$ upper and lower confidence limits.

Trial site - Field tests were conducted in the two neighboring communities (Arimatea and Nueva Galilea) of the 
municipality of Palenque, Chiapas, Mexico, close to the border with Guatemala (Fig. 1). These communities are 8 $\mathrm{km}$ apart and about $29 \mathrm{~km}$ from the city of Palenque.

Insecticides and spraying - Designated houses were sprayed with lambdacyhalothrin WP and SC using $8 \mathrm{~L}$ Hudson X-pert spraypacks. All internal wall and roofs surfaces were sprayed. A total of 60 houses were treated in the two communities. Spraying was completed in five days and was done in autumn (November 1997) as follows: (1) three concentrations were prepared with the insecticides WP $\left(8.6,16.7,23.7 \mathrm{mg}\right.$ a.i. $\left./ \mathrm{m}^{2}\right)$ and $\mathrm{SC}(1.876$, $3.752,5.628 \mathrm{mg}$ a.i. $\left./ \mathrm{m}^{2}\right)$, according to the values for $\mathrm{LC}_{90}$ obtained in the susceptibility tests. Each concentration was sprayed on at least 10 houses following Mexican regulations (NOM-049-SSA1-1993); (2) before the treatment the kitchen utensils, food, personal clothing and bed clothing were removed from the houses. Domestic animals were taken far away from the application area. The owners were instructed to keep doors and windows closed

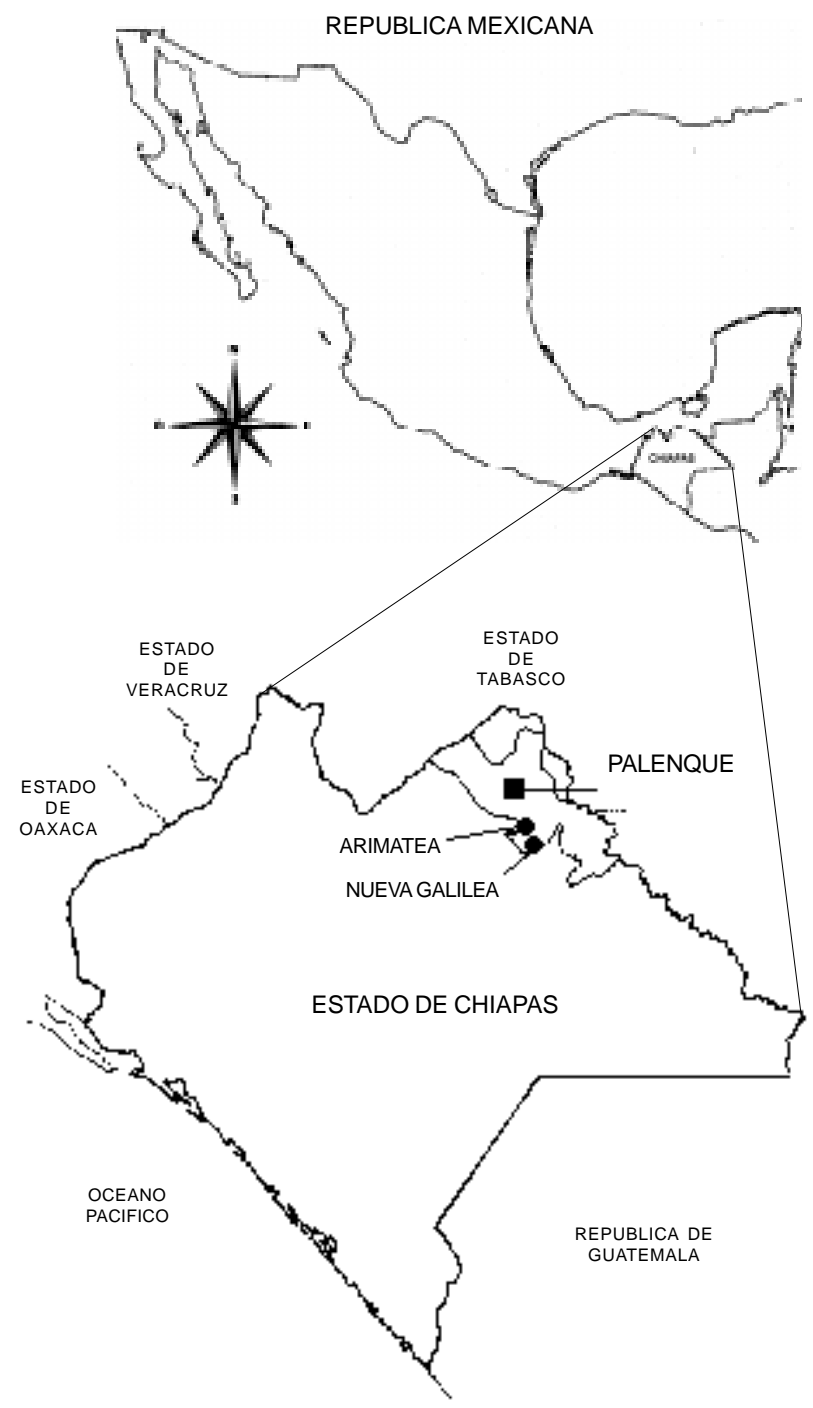

Fig. 1: map of the Mexican Republic, showing the Chiapas State and the communities studies. during $2 \mathrm{~h}$ after the application of the insecticide and then to ventilate the houses before transferring the utensils back to the interior; (3) at the moment of spraying on the palm roofs, three filter papers were pinned at various heights to roofs of each of three houses selected at random. After spraying, these papers were sealed into individual plastic bags to determine the amount of insecticide applied by differences of weight.

Evaluation of the residual effects - Evaluated at $24 \mathrm{~h}$ and at $1,3,6,9,12,15$ and 18 months after spraying by exposing to 24 and $48 \mathrm{~h}$ of ten $R$. prolixus nymphs on the indoor insecticide-treated surfaces of palm leaves. It was carried out by holding the insects in place by using the AGA boxes attached to the treated surfaces of the roofs (Cruzado \& Molina 2000). After 24 h, insects were removed, mortality rates were recorded and live insects were transferred onto filter paper and observed in the laboratory for seven days in order to observe the delayed effect of the insecticide. The tests were always performed fixing the boxes to different positions on the same roofs of each of the test houses. A control group was established in houses not sprayed.

\section{RESULTS}

Householders were generally pleased by the spraying. All were satisfied with the applied product, with several noting that it did not smell nor leave any obvious deposit. Many were particularly pleased at the rapid action against cockroaches and scorpions that fell shortly after spraying. However they did not allow us to search for triatomines inside their houses.

Table I shows the results of the susceptibility assays.

The dose utilized in the field spraying were: the dose 1 of WP was of 8.6; dose 2 was of 16.7 and the dose 3 was of $23.7 \mathrm{mg}$ a.i. $/ \mathrm{m}^{2}$ (one, two and three times the $\mathrm{LC}_{\mathrm{g} 9}$ ). For SC the dose were $1.876,3.752$ and $5.628 \mathrm{mg}$ a.i. $/ \mathrm{m}^{2}$.

The amount of insecticide applied inside the houses determined with filter papers is shown in Table II.

The first evaluation of the residual effect of the insecticides were performed at $24 \mathrm{~h}$ after spraying by exposing fifth-instar $R$. prolixus on three palm roofs resulting in a $100 \%$ mortality rate (for WP in dose 1). Evaluation of the residual effects was repeated one, three and six months after the insecticide application at the same houses, $100 \%$ effectiveness was observed up to six months after spraying. After nine months the effectiveness began to decline slightly (93.3\%; Fig. 2). It was also observed that in dose 2 the effectiveness was $100 \%$ up to 12 months, beginning to decline after 15 months to $93.3 \%$. In dose 3, the effectiveness was $100 \%$ up to 12 months, beginning to decline after 15 months to $96.6 \%$. With the SC, it was observed that for dose one the effectiveness was $100 \%$ up to three months, beginning to decline after six months to $96.6 \%$ and to $33.3 \%$ after 18 months. It was also observed that for dose two the effectiveness was $100 \%$ up to 9 months, beginning to decline slightly to $96.6 \%$ after 12 months and to $63.3 \%$ after 18 months. For dose 3, 100\% effectiveness was observed up to 12 months, beginning to decline to $93.3 \%$ after 15 months and to $86.6 \%$ after 18 months, this is illustrated in Figs 3 and 4. 
TABLE I

Susceptibility assays using fifth-instar Rhodnius prolixus nymphs exposed to the two formulations of the lambdacyhalothrin applied on palm leaves

\begin{tabular}{lcccc}
\hline Insecticides & $\begin{array}{c}\text { Dose } \\
\text { mg a.i./m }\end{array}$ & $\begin{array}{c}\% \\
\text { mortality }\end{array}$ & $\begin{array}{c}\text { Lethal concentrations } \\
\mathrm{mg} \mathrm{a}^{2} . / \mathrm{m}^{2}\end{array}$ & $\begin{array}{c}95 \% \\
\text { confidence limits }\end{array}$ \\
\hline Demand® & 0.156 & 40 & $\mathrm{LC}_{50}=0.299$ & $0.087<\mathrm{LC}_{50}<0.52$ \\
& 0.312 & 50 & $\mathrm{LC}_{90}=1.87$ & $0.94<\mathrm{LC}_{90}<20.3$ \\
& 0.624 & 60 & & \\
& 1.248 & 80 & & $1.5<\mathrm{LC}_{50}<4.0$ \\
Commodore ${ }^{\circledR}$ & 1.497 & 40 & $\mathrm{LC}_{50}=2.37$ & $4.37<\mathrm{LC}_{90}<169.8$ \\
& 1.498 & 50 & $\mathrm{LC}_{90}=8.5$ & \\
& 3.121 & 70 & & \\
\hline
\end{tabular}

Ten fifth-instar $R$. prolixus nymphs were exposed to the insecticides on surfaces of $80.1 \mathrm{~cm}^{2}$. The $\mathrm{LC}_{50}$ and $\mathrm{LC}_{90}$ (lethal concentration) were plotted in a log.probit graph, calculations made with a computer program (Raymond 1996).

TABLE II

Amounts of insecticides in filter paper placed on the palm roofs during spraying

\begin{tabular}{|c|c|c|c|c|c|c|}
\hline \multirow{2}{*}{$\begin{array}{l}\text { Lambdacyhalothrin } \\
\text { formulations }\end{array}$} & \multicolumn{2}{|c|}{ Dose one $\mathrm{mg}$ a.i. $/ \mathrm{m}^{2}$} & \multicolumn{2}{|c|}{ Dose two $\mathrm{mg}$ a.i. $/ \mathrm{m}^{2}$} & \multicolumn{2}{|c|}{ Dose three $\mathrm{mg}$ a.i. $/ \mathrm{m}^{2}$} \\
\hline & Obtained & Mean & Obtained & Mean & Obtained & Mean \\
\hline WP 10 & $\begin{array}{r}8.04 \\
10.34 \\
9.19\end{array}$ & $\begin{array}{l}9.19 \\
(8.6)^{a}\end{array}$ & $\begin{array}{l}16.08 \\
18.38 \\
17.23\end{array}$ & $\begin{array}{l}17.23 \\
(16.7)\end{array}$ & $\begin{array}{l}25.28 \\
24.13 \\
27.57\end{array}$ & $\begin{array}{l}25.66 \\
(23.7)\end{array}$ \\
\hline SC 2.5 & $\begin{array}{l}1.87 \\
2.11 \\
1.96\end{array}$ & $\begin{array}{c}1.98 \\
(1.876)\end{array}$ & $\begin{array}{l}4.6 \\
4.5 \\
4.1\end{array}$ & $\begin{array}{c}4.4 \\
(3.752)\end{array}$ & $\begin{array}{l}6.84 \\
7.12 \\
6.24\end{array}$ & $\begin{array}{c}6.73 \\
(5.628)\end{array}$ \\
\hline
\end{tabular}

The amount insecticide in filter papers was calculated by differences of weight; $a$ : target dose in brackets

\section{DISCUSSION}

Synthetic pyrethroids such as permethrin and deltamethrin seem to retain their superficial toxicity for much longer than organochlorines, organophosphates or carbamates. Field trials with these compounds, at much lower doses than those used for BHC (Lindane), show that a single application can keep houses free from apparent infestation for several months, in some cases more than a year (Pinchin et al. 1980, 1981, Schofield 1985). These compounds, although more expensive (nearly 1020 times the price of the BHC), offer an excellent alternative for the control of triatomines. Particularly, the insecticidal activity of lambdacyhalothrin on $R$. prolixus is superior to that of other pyrethroids (Oliveira-Filho 1999).

Assays of susceptibility with Demand $₫$ and Commodore ${ }^{\circledR}$ - In Table I, we can observe that the concentrations obtained for the Demand $®$ formulation are 4-8 times smaller $\left(\mathrm{LC}_{50}=0.299\right.$ and $\left.\mathrm{LC}_{90}=1.87 \mathrm{mg} / \mathrm{m}^{2}\right)$ that those obtained for Commodore ${ }^{\circledR}\left(\mathrm{LC}_{50}=2.37\right.$ and $\mathrm{LC}_{90}=8.5$ $\left.\mathrm{mg} / \mathrm{m}^{2}\right)$. In the same way Demand $®$ resulted in the same effectiveness with 16 times less product and Commodore $\AA$ with 3.5 times less than the 30 a.i. $\mathrm{mg} / \mathrm{m}^{2}$, used by Ferro et al. (1995).

The above-mentioned confirms the necessity of carrying out tests of susceptibility of local triatomines to each new insecticide formulation on different materials.
Residual effects of insecticides - Encouraging results were obtained with the two commercial preparations. With WP in dose $1\left(8.6 \mathrm{mg} / \mathrm{m}^{2}\right)$ an absolute efficiency was obtained for up to 15 months after its application, at which time a significant decline was observed in its residual efect on palm leaves (test $\mathrm{z}$ ). In the case of SC $\left(1.876 \mathrm{mg} / \mathrm{m}^{2}\right)$ an absolute efficiency was obtained for up to 9 months after its application, at which time a significant decline was observed in it efficiency (Fig. 2). Carrying out this same test for dose 2 , for SC $\left(3.752 \mathrm{mg} / \mathrm{m}^{2}\right)$, an absolute efficiency was obtained for up to 15 months after its application, while for $\mathrm{WP}\left(16.7 \mathrm{mg} / \mathrm{m}^{2}\right.$ ) for up to $18 \mathrm{months}$ (Fig. 3). These same results were obtained for doses 3 of both preparations.

The references on the use of pyrethroid insecticides report for studies conducted in Paraguay and Brazil an absolute effectiveness for up to 18 months with the lambdacyhalothrin (Oliveira-Filho et al. 1988, Ferro et al. 1995) and Mazariego-Arana (1997) working with alfacypermethrin and lambdacyhalothrin found an absolute effectiveness for up to 14 months in a laboratory study carried out in Mexico city.

From our results, we consider that for WP the application of a dose of $8.6 \mathrm{mg} / \mathrm{m}^{2}$ could be used to keep palm roofs free $R$. prolixus in the localities mentioned. In the case of SC, an application of a dose of $3.752 \mathrm{mg} / \mathrm{m}^{2}$ gave the same results for up to 15 months. Since we found 


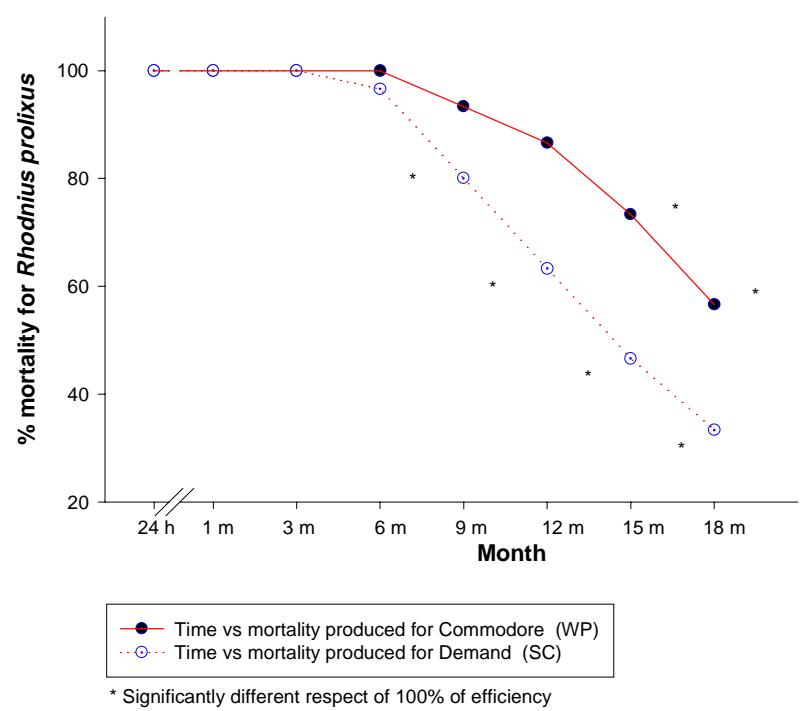

Fig. 2: percent of mortality on the fifth-instar nymphs of Rhodnius prolixus bugs after $24 \mathrm{~h}$ of exposure to the treated palm leaves roofs with lambdacyhalothrin dose one of SC (1.87) and WP (8.6 mg a.i. $/ \mathrm{m}^{2}$ )

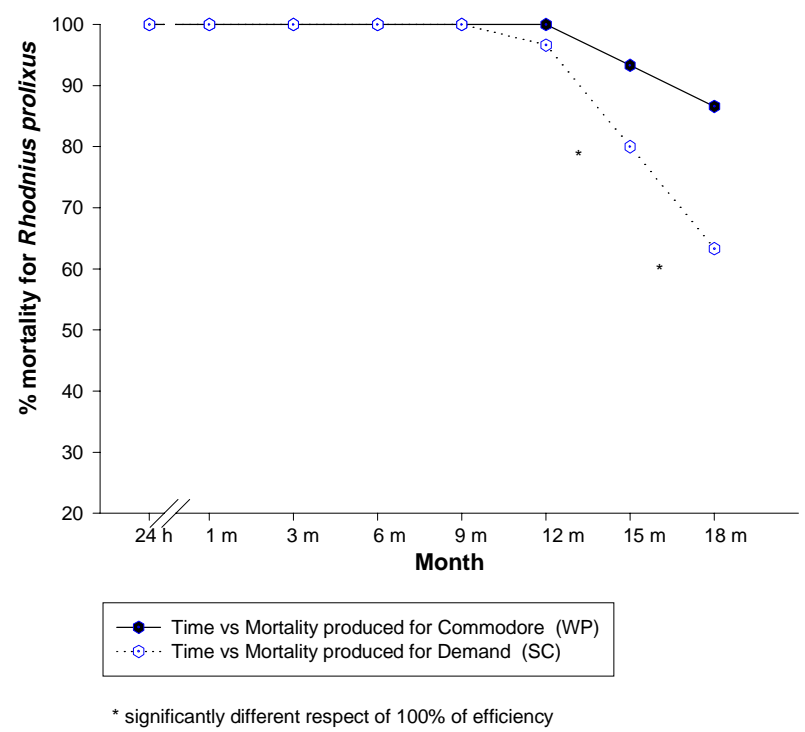

Fig. 3: percent of mortality on the fifth-instar nymphs of Rhodnius prolixus bugs after $24 \mathrm{~h}$ of exposure to the treated palm leaves roofs with lambdacyhalothrin dose two of SC (3.75) and WP (16.7 $\mathrm{mg}$ a.i. $/ \mathrm{m}^{2}$ )

similar effects with the compounds tested, the selection of the doses and of the commercial preparation depends largely on their costs.

$R$. prolixus appears as a highly susceptible organism to both tested products in lower dosages than insecticides currently employed against other domestic triatomines in Chagas Disease Control Programmes, our results may contribute to determine the most effective formulations when using the pyrethroid insecticide lambdacyhalothrin.

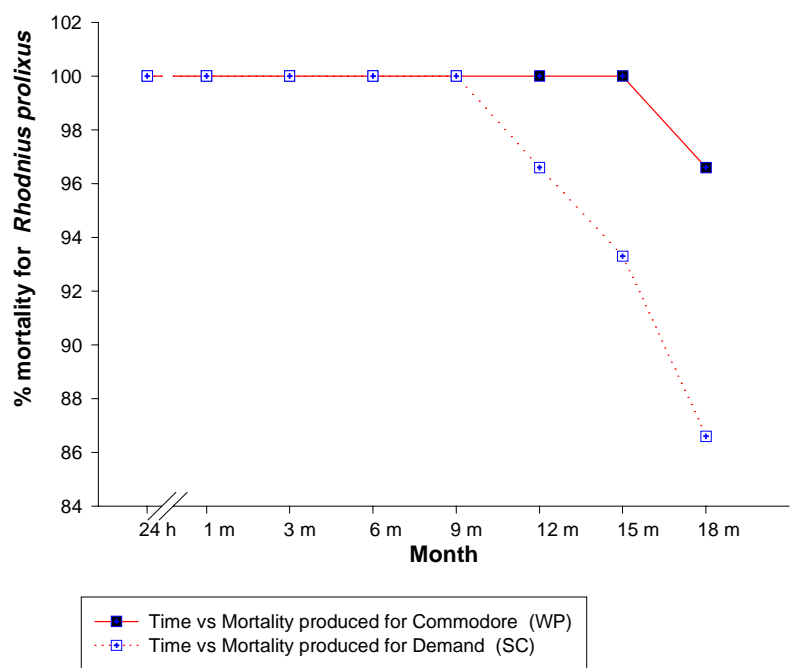

Fig. 4: percent of mortality on the fifth-instar nymphs of Rhodnius prolixus bugs after $24 \mathrm{~h}$ of exposure to the treated palm leaves roofs with lambdacyhalothrin dose three of SC (5.63) and WP $\left(23.7 \mathrm{mg}\right.$ a.i. $\left./ \mathrm{m}^{2}\right)$

\section{ACKNOWLEDGEMENTS}

To Zéneca Mexicana S. A., for the donation of the insecticide formulation; to the Centro de Investigación de Paludismo/ SS for the training and advice in the use of the spraypacks. To Amparo Pérez-López, Herminio Escobar-Castillo, David PérezGallegos, Izael Aguirre-López, Carlos Hiram Molina-Ventura and Fausto Raúl Cruzado-Mazariego for laboratory and field assistance. To the local authorities of Palenque, Chiapas for their support, and to the people of the communities of Arimatea and Nueva Galilea for their cooperation and trust.

\section{REFERENCES}

Acevedo F, Godoy E, Schofield CJ 2000. Comparison of intervention strategies for control of Triatoma dimidiata in Nicaragua. Mem Inst Oswaldo Cruz 95: 867-871.

Cruzado-Mazariego FR, Molina-Ventura CH 2000. Pruebas de Campo para el Control en la Transmisión de Trypanosoma cruzi a Través del Insecticida Piretroide Lambdacialotrina en Casas-habitación de Localidades del Municipio de Palenque, Chiapas, Thesis, Facultad de Ciencias Químicas, Universidad Autónoma de Chiapas, México.

Dias JCP, Schofield CJ 1999. The evolution of Chagas disease (American tripanosomiasis) control after 90 year since Carlos Chagas discovery. Mem Inst Oswaldo Cruz 94 (Suppl. I): 103-121.

Dujardin JP, Muñóz M, Chávez T, Ponce C, Moreno J, Schofield CJ 1998. The origin of Rhodnius prolixus in Central America. Med Vet Entomol 12: 113-115.

Ferro AE, Rojas de A, Ferreira ME, Simancas LC, Rios LS, Rosner M 1995. Residual effect of lambdacyhalothrin on Triatoma infestans. Mem Inst Oswaldo Cruz 90: 415-419.

Mazariego-Arana MA 1997. Evaluación del Control de Triatominos (Insecta: Hemiptera) a través de Insecticidas, MSc Thesis, Escuela Nacional de Ciencias Biológicas, Instituto Politécnico Nacional, México.

Moncayo A 1999. Progress towards interruption of transmisión of Chagas disease. Mem Inst Oswaldo Cruz 94 (Suppl. I): 401-404. 
NOM-Norma Oficial Mexicana, NOM-049-SSA1-1993. Requisitos sanitarios para el almacenamiento, distribución, venta y aplicación de plaguicidas de uso doméstico, Secretaría de Salud y Asistencia, México.

Oliveira-Filho AM 1999. Differences of susceptibility of five triatomine species to pyrethroid insecticides - Implications for Chagas disease vector control. Mem Inst Oswaldo Cruz 94 (Suppl. 1): 425-428.

Oliveira-Filho AM, Figueiredo MJ, Melo MTV, Santos CE, Silva EL, Dias JCP, Teixeira-Neto I, Brasil LA, Bastos LC, Deus LF 1988. Evaluation of the pyrethroid lambdacyhalothrin (OMS 3021) as a control agent for triatomines. 5th Meeting for Applied Research into the Control of Chagas' Disease, Araxá, Minas Gerais, Brazil, Appendix 6, Abstract A. 2-21.

OPS-Oficina Panamericana de Salud 1984. Boletín Técnico No. 26, Enfermedad de Chagas, México.

Pinchin R, de Oliveira-Filho AM, Fanara DM, Gilbert B 1980. Ensaio de campo para avaliação das posibilidades de uso da decametrina (OMS 1998) no combate a triatomineos. Rev
Bras Malariol Doenças Trop 32: 36-41.

Pinchin R, de Oliveira-Filho AM, Gilbert B 1981. Field trial of permethrin for the control of Triatoma infestans. Bull PAHO 15: 370-376.

Ponce C 1999. Elimination of the vectorial transmission of Chagas disease in Central American countries: Honduras. Mem Inst Oswaldo Cruz 94 (Suppl. I): 417-418.

Raymond M 1996. Probit analysis program. Laboratoire de Genetique Institut de la Science de l'Evolution. U.S.T.L., Place E. Bataillon 34060, Montepellier, Cedex France.

Ryckman RE 1951. Laboratory culture of triatominae with observations on behavior and a new feeding device. J Parasitol 83: 210-214.

Schofield CJ 1985. Control of Chagas disease vectors. British Med Bull 41: 187-194.

Schofield CJ, Dujardin JP 1997. Chagas disease vector control in Central America. Parasitol Today 13: 141-144.

WHO-World Health Organization 1991. Control of Chagas Disease. Report of a WHO Expert Committee, Technical Report Series 811, Geneva, 95 pp. 